\title{
Interaction between isoprenaline and aminophylline in asthma
}

\author{
I. A. CAMPBELL ${ }^{1}$, W. G. MIDDLETON, G. J. R. McHARDY, MARGARET V. SHOTTER, \\ ROBIN McKENZIE, AND A. B. KAY ${ }^{2}$
}

From the University Department of Respiratory Diseases, City Hospital, Edinburgh, the University Department of Statistics, Edinburgh, and the South-East Scotland Regional Blood Transfusion Service, Royal Infirmary, Edinburgh

Campbell, I. A., Middleton, W. G., McHardy, G. J. R., Shotter, Margaret V., McKenzie, R., and Kay, A. B. (1977). Thorax, 32, 424-428. Interaction between isoprenaline and aminophylline in asthma. Using a factorially designed study, 38 patients with bronchial asthma received a single dose of either isoprenaline by inhalation (9), aminophylline intravenously (10), isoprenaline and aminophylline (11), or placebo (8). The maximum expiratory flow ( $\mathrm{V} \max$ ), the maximum expiratory flow at $50 \%$ of vital capacity $\left(\mathbb{V} \max _{50}\right)$, and the concentrations of plasma cyclic AMP were measured at time intervals up to two hours. The combination of isoprenaline and aminophylline acted synergistically in terms of the percent increase in $V \max _{50}$. However, this was statistically significant only at 20 minutes. Plasma cyclic AMP concentration rose with a similar time course of response to the changes in small airways. The elevations in plasma cyclic AMP observed with the drug combination were higher than those for the individual drugs at $10,20,30$, and 60 minutes but these differences were not statistically significant. These observations support the concept that changes in bronchial smooth muscle tone are mediated by concentrations of cyclic nucleotides and that combinations of isoprenaline and aminophylline, rather than the administration of each drug separately, may have therapeutic advantages in the treatment of bronchial asthma.

It is common practice to use beta-adrenergic stimulants and methyl xanthines in the treatment of bronchial asthma. The studies of Robison et al. (1971) suggest that the beta-adrenergic effects of catecholamines are mediated through $3^{\prime} 5^{\prime}$ cyclic adenosine monophosphate (cyclic AMP), the intracellular 'second messenger'. Methyl xanthines inhibit phosphodiesterase, the enzyme which inactivates cyclic AMP (Butcher and Sutherland, 1962), and it is proposed (Leading article, 1970) that methyl xanthines and beta-adrenergic agents may produce bronchodilatation by increasing the level of cyclic AMP in bronchial and bronchiolar smooth muscle.

Drugs which individually act at different points in the metabolic pathway of a compound in such a way as to increase the amount of that compound may, when used together, produce an increase greater than the sum of the increases produced

\footnotetext{
${ }^{1}$ Present address: Respiratory Department, Bristol Royal Infirmary
} ${ }^{2}$ University Department of Pathology, Edinburgh by each drug alone, that is, they may interact synergistically (Veldstra, 1956). There is evidence in vitro for synergy between beta-adrenergic agents and methyl xanthines (Rall and West, 1963; Lichtenstein and Margolis, 1968; Kaliner et al., 1971). The present study was designed to establish whether such interaction could be demonstrated in vivo in man. We studied the effects of inhaled isoprenaline and intravenous aminophylline on the airways and on heart rate. The level of cyclic AMP in plasma was also measured as it has been described as a convenient index of effects of drugs on tissue levels of cyclic AMP (Ball et al., 1972; Karlberg et al., 1974; Wehman et al., 1974).

\section{Patients and methods}

Thirty-eight patients were studied. All patients had airways obstruction and, at some time in the past, had shown a $20 \%$ or more increase in 
$\mathrm{FEV}_{1}$ after inhaled isoprenaline or salbutamol. At the time of study they were symptomatically well and were therefore considered to be in a stable state. Informed consent was obtained from each patient, and the protocol was approved by the Ethical Committee of the City Hospital, Edinburgh.

\section{DESIGN AND DOSAGE}

A factorial design permitting the detection of drug interaction (Armitage, 1971) was used. Patients were allocated in random order to one of four treatments:

1 Placebo inhaler plus placebo injection (P), 8 patients;

2 Isoprenaline inhaler plus placebo injection (I), 9 patients;

3 Placebo inhaler plus aminophylline injection (A), 10 patients;

or

4 Isoprenaline inhaler plus aminophylline injection $(\mathrm{I}+\mathrm{A}), 11$ patients.

The placebo inhaler delivered inactive propellant only and the placebo injection consisted of $10 \mathrm{ml}$ of normal saline. The inhalers and ampoules were prepared by the hospital pharmacist in such a way that active and placebo preparations were indistinguishable. Two 'puffs' were taken from the isoprenaline inhaler $(0.16-0.18 \mathrm{mg}$ ex valve) and the intravenous dose of aminophylline was $250 \mathrm{mg}$ in $10 \mathrm{ml}$. The treatments were given in a double-blind fashion.

\section{METHODS}

Maximum expiratory flow volume (MEFV) curves were recorded at the mouth with a Fleisch pneumotachograph and an integrator, displayed on a storage oscilloscope (Tektronix 5100), and photographed on Polaroid film. The system was calibrated for volume with a Gaensler spirometer, which had previously been calibrated by water displacement, and for flow using a rotameter and vacuum cleaner. Calibration was performed before, during, and at the end of each experiment. The maximum expiratory flow rate $(V \max )$ and the maximum expiratory flow rate at $50 \%$ of forced vital capacity $\left(\mathbf{V} \max _{\tilde{5} 0}\right)$ were measured from two acceptable records of the MEFV curve and the greater value of each index was used for analysis. Obvious differences in the forced vital capacity or distortion by coughing were the usual reasons for considering the records unacceptable. Heart rate was measured from lead II of the electrocardiogram (ECG) recorded for 30 seconds on a Sharp MT23 machine. Plasma cyclic AMP was measured by the com- petitive protein binding assay of Gilman (1970) using the materials supplied by the Radiochemical Centre, Amersham. Blood was drawn into ethylenediaminetetracetate (EDTA) to a final concentration of $0.005 \mathrm{M}$ and the plasma was separated and stored at $-80^{\circ} \mathrm{C}$. The samples were thawed once and the proteinaceous material removed by precipitation with $67 \%$ ethanol. In order to show that the drugs or their metabolites did not influence the assay 8 picomoles of cyclic AMP were added to $1 \mathrm{ml}$ aliquots of the seven plasma samples from a patient who received the combination of isoprenaline and aminophylline. Values obtained gave the expected increase above aliquots to which no cyclic AMP had been added.

\section{PROCEDURE}

The patients were instructed not to use any bronchodilator preparations for at least six hours before the investigation. A Medicut cannula was inserted into a forearm vein. The patient remained at rest in an armchair for at least 15 minutes and then the ECG was recorded for 30 seconds. Five millilitres of blood were drawn and two MEFV curves recorded with the patient in the sitting position. Two puffs of isoprenaline or of a placebo inhaler were then taken by the patient during the first half minute of a five-minute infusion of either aminophylline or saline. During the last 30 seconds of the infusion the ECG was recorded. Blood was taken immediately after the end of infusion, that is, at time five minutes, and two MEFV curves were recorded. Measurements and samples were repeated $10,20,30,60$, and 120 minutes from the start of the infusion.

One patient in the placebo group, one in the $\mathrm{A}$ group, and two in the I+A group fainted during or immediately after the injection. All four insisted on continuing the investigation and their results are included in the analysis.

\section{STATISTICAL ANALYSIS}

The data obtained were subjected to an analysis of variance for a factorial experiment (Armitage, 1971). This analysis provided an assessment of the effects of isoprenaline, aminophylline, and of the combination of the two drugs. An interaction term was derived at each time and its standard error was calculated. If the interaction term was larger than twice its own standard error (that is, was significantly different from zero), the drugs had interacted synergistically.

\section{Results}

The mean pre-treatment values of $\mathbf{V} \max _{50}$, 
Table Mean pre-treatment values $( \pm S E)$ of $\dot{V}$ max, $\dot{V} \max _{50}$, heart rate, and plasma cyclic $A M P$

\begin{tabular}{|c|c|c|c|c|}
\hline & Placebo & Isoprenaline & Aminophylline & $\begin{array}{l}\text { Isoprenaline } \\
+ \\
\text { aminophylline }\end{array}$ \\
\hline $\begin{array}{l}\text { No. of patients } \\
\dot{V} \max _{50}(1 / \mathrm{sec}) \\
\dot{V} \max (1 / \mathrm{sec}) \\
\text { Heart rate per min } \\
\text { Cyclic AMP (nanomoles/l) }\end{array}$ & $\begin{array}{l}8 \\
1 \cdot 32( \pm 0 \cdot 25) \\
4 \cdot 36( \pm 0 \cdot 63) \\
75( \pm 4) \\
11 \cdot 8( \pm 2 \cdot 15)\end{array}$ & $\begin{array}{l}9 \\
1 \cdot 02( \pm 0 \cdot 27) \\
3 \cdot 82( \pm 0 \cdot 52) \\
80( \pm 3) \\
11 \cdot 3( \pm 1 \cdot 5)\end{array}$ & $\begin{array}{l}10 \\
1 \cdot 53( \pm 0 \cdot 22) \\
4 \cdot 42( \pm 0 \cdot 45) \\
83( \pm 5) \\
11 \cdot 7( \pm 1 \cdot 7)\end{array}$ & $\begin{array}{l}11 \\
1 \cdot 13( \pm 0 \cdot 11) \\
3 \cdot 85( \pm 0 \cdot 2) \\
71( \pm 4) \\
9 \cdot 7( \pm 1 \cdot 8)\end{array}$ \\
\hline
\end{tabular}

$V$ max, heart rate, and plasma cyclic AMP for each group are shown in the Table. The differences between groups were not statistically significant.

The means of the percentage increases in $V \max _{50}$ produced by each treatment are shown in Figure 1. The placebo group remained much the same over the two hours. The combination I + A produced increases which were larger than those produced by either drug alone, but at 60 minutes and 120 minutes the differences between $\mathrm{A}$ and $\mathrm{I}+\mathrm{A}$ were not significant at the $5 \%$ level. Although I+A was significantly different from the other three groups at all other times, it was only at 20 minutes that the interaction term was greater than twice its standard error. At 5, 10,

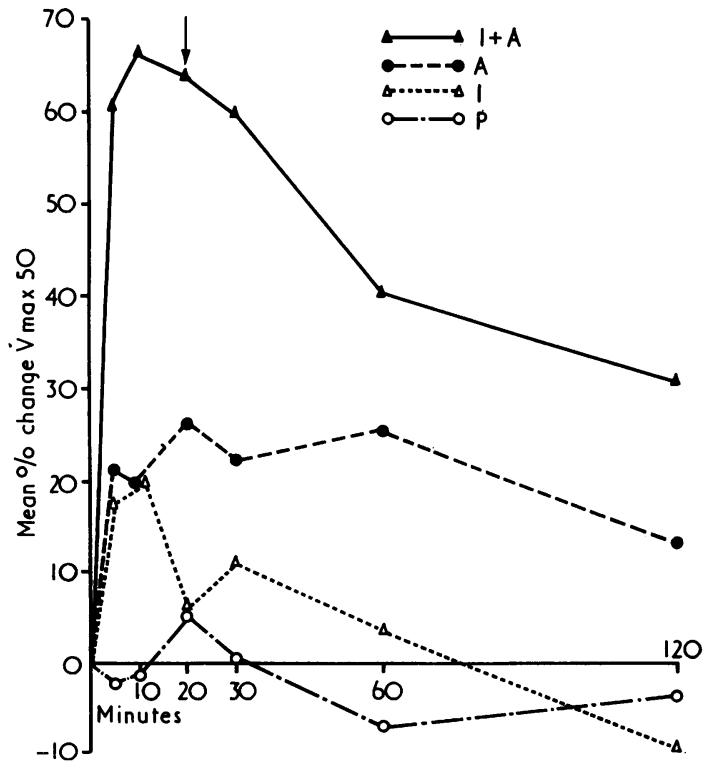

Fig. 1 Mean percent change in $\dot{V} \max _{50}$. For the sake of clarity standard errors are not shown. Significant differences at each time are stated in the text, and the arrow indicates the time at which interaction between $I$ and $A$ was found. and 30 minutes the suggestion that the combination was synergistic was not significant at the $5 \%$ level.

The same trend towards a synergistic effect on $V$ max was apparent up to 30 minutes after treatment (Fig. 2), but this trend did not achieve statistical significance. At 60 and 120 minutes the effects of $\mathrm{I}+\mathrm{A}$ were greater than those of I alone $(\mathrm{P}<0.05)$ but were much the same as $\mathrm{A}$ alone.

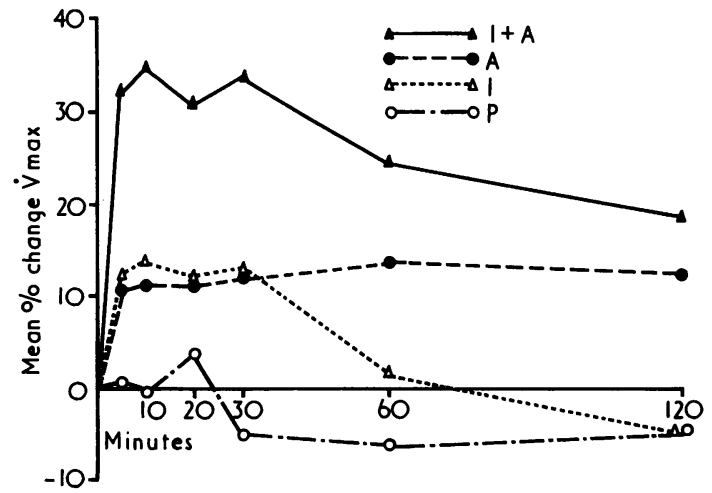

Fig. 2 Mean percent change in $\dot{V} \max$

The effects on heart rate are shown in Figure 3. Neither synergy nor addition occurred. I, A, and I+ A produced increases which were not statistically distinguishable from each other. At five

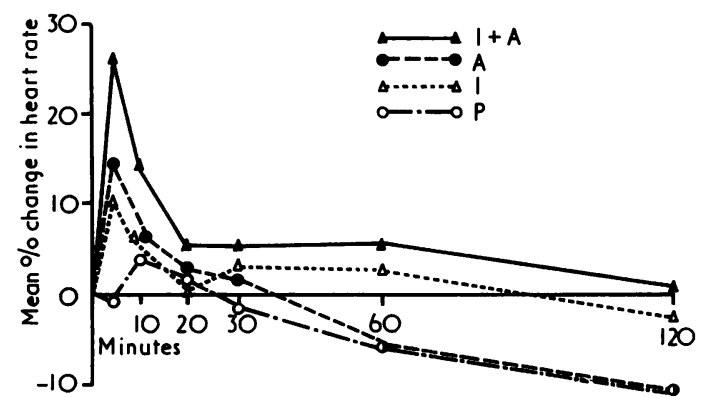

Fig. 3 Mean percent change in heart rate. 
minutes $\mathrm{A}$ and $\mathrm{I}+\mathrm{A}$ were different from placebo $(P<0.05)$ but the changes resulting from I alone were at no time significantly different from placebo.

$\mathrm{I}, \mathrm{A}$, and $\mathrm{I}+\mathrm{A}$ produced similar changes in plasma cyclic AMP (Fig. 4), and these changes paralleled the time course of the changes in the airways. At 10, 20,30, and 60 minutes the combination $\mathrm{I}+\mathrm{A}$ produced changes greater than those produced by each drug alone but the differences were not statistically significant.

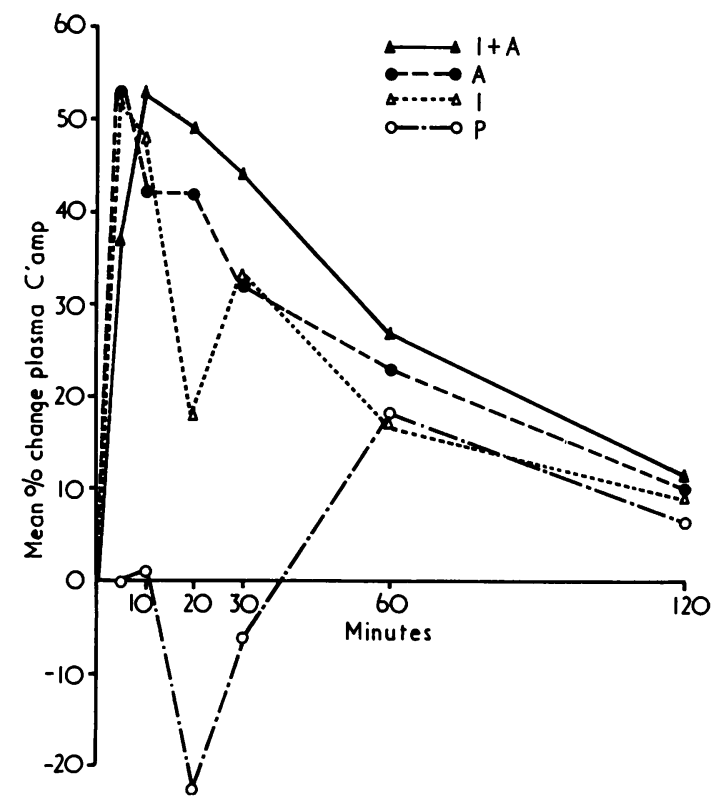

Fig. 4 Mean percent change in concentration of cyclic $A M P$ in plasma.

\section{Discussion}

Synergy between two drugs is said to occur if the effect produced when they are given together is greater than the sum of their effects when given individually. It is generally accepted that a displacement to the left of the dose-response curve of one drug by another drug indicates synergistic interaction. To be conclusive this shift should be significantly greater than the response to the second drug alone. An alternative method for investigating interaction, which avoids the necessity of establishing dose response curves, is to use single, fixed doses of the drugs in a factorially designed experiment (Armitage, 1971; Pearson et al., 1976), and we have used this latter method.

Hume and Rhys Jones (1961) observed an addi- tive effect of isoprenaline and aminophylline on $\mathrm{FEV}_{1}$ in six patients. Pihlajamäki et al. (1972) examined the effects of glyphylline and isoprenaline singly and in combination, and Cohen and Elizabeth (1974) studied ephedrine and theophylline, but none of these studies was designed in a way which would allow the observed effects to be analysed quantitatively for synergy. Using a factorial design, we have now shown a synergistic bronchodilator effect between isoprenaline and aminophylline on $V \max _{50}$ but not on $V \max$. While it is possible that reducing variation by studying larger numbers of patients or by using a within-patient comparison of the drugs might have resulted in the demonstration of synergistic interaction on $V \max$ it is also possible that the different findings for $V \max$ and $V \max _{50}$ represent a true difference of the effects of the drugs at different sites in the airways, because it has been argued that changes in maximum expiratory flow rate at $50 \%$ forced vital capacity reflect changes in calibre of the smaller airways (McFadden and Linden, 1972).

It would seem that plasma levels of cyclic AMP reflect only broadly changes occurring at tissue level for although the time courses of the plasma cyclic AMP changes were similar to those of the airways we have found no difference between the effect of I, A, and I+ A on plasma cyclic AMP. This is not entirely surprising when one considers that the level of plasma cyclic AMP is only $1 \%$ of the level in tissues (Karlberg et al., 1974) and that the plasma concentration of cyclic AMP is thought to be the result of a leakage of cyclic AMP from cells into the extracellular space (Broadus et al., 1971). Nevertheless the marked response in plasma cyclic AMP 10 minutes after the administration of drugs used in treating acute asthma may have important therapeutic implications. In status asthmaticus the response to betaadrenergic stimulants is sometimes impaired or absent, and it has been suggested that alphaadrenergic blocking drugs can restore betaresponsiveness (Palmer et al., 1974; Patel and Kerr, 1975). Furthermore, some patients with chronic asthma appear to have lost their ability to respond to beta-adrenergic stimulants, and Ellul-Micallef and Fenech (1975) have shown that this responsiveness can be restored by administering corticosteroids. The measurement of the responses of plasma cyclic AMP to beta-adrenergic stimulants might therefore provide an objective means of deciding when beta-responsiveness is no longer present in a clinical situation in which tests of ventilatory function are either too insensitive or too impractical to be a useful index of response. 
Neither synergy nor addition was found in the action of the drugs on heart rate. At rest heart rate is controlled predominantly by the parasympathetic nervous system (Robinson et al., 1953; Robinson et al., 1966) and reflex parasympathetic changes might be expected to redress changes induced by isoprenaline and aminophylline, thereby making it difficult to show interaction of these drugs on heart rate. However, both $\mathrm{A}$ and $\mathrm{I}+\mathrm{A}$ produced a significant rise in heart rate five minutes after treatment. In status asthmaticus such a rise might be unacceptable unless oxygen was available to counteract the possible worsening of hypoxaemia that might result.

Our demonstration of the synergistic interaction between a beta-adrenergic stimulant and a methyl xanthine on the airways of man in vivo supports the concept that cyclic AMP may participate in the events leading to bronchodilatation and provides a rationale for their combined use in the treatment of asthma.

We thank Miss S. Merchant and Mr. G. Goodenough for expert technical assistance, Professor J. W. Crofton and Dr. A. C. Douglas for permission to study patients under their care, and Riker Laboratories for financial assistance.

\section{References}

Armitage, P. (1971). Statistical Methods in Medical Research, pp. 226-239. Blackwell, Oxford.

Ball, J. H., Kaminsky, N. I., Hardman, J. G., Broadus, A. E., Sutherland, E. W., and Liddle, G. W. (1972). Effects of catecholamines and adrenergic-blocking agents on plasma and urinary cyclic nucleotides in man. Journal of Clinical Investigation, 51, 21242129.

Broadus, A. E., Hardman, J. G., Kaminsky, N. I., Ball, J. H., Sutherland, E. W., and Liddle, G. W. (1971). Extracellular cyclic nucleotides. Annals of the New York Academy of Sciences, 185, 50-66.

Butcher, R. W., and Sutherland, E. W. (1962). Adenosine $3^{\prime} 5^{\prime}$ phosphate in biological materials. I. Purification and properties of cyclic $3^{\prime} 5^{\prime}$ nucleotide phosphodiesterase and use of this enzyme to characterise adenosine $3^{\prime} 5^{\prime}$ phosphate in human urine. Journal of Biological Chemistry, 237, 12441250.

Cohen, B. M., and Elizabeth, N. J. (1974). Sympathomimetic/xanthine broncholysis in obstructive ventilatory disorders. International Journal of Clinical Pharmacology, 9, 6-15.

Ellul-Micallef, R., and Fenech, F. F. (1975). Effect of intravenous prednisolone in asthmatics with diminished adrenergic responsiveness. Lancet, 2, 1269-1271.

Gilman, A. G. (1970). A protein binding assay for adenosine $3^{\prime} 5^{\prime}$-cyclic monophosphate. Proceedings of the National Academy of Sciences, 67, 305-312.
Hume, K. M., and Rhys Jones, E. (1961). The response to bronchodilators in intrinsic asthma. Quarterly Journal of Medicine, 30, 189-199.

Kaliner, M. A., Orange, R. P., Koopman, W. J., Austen, K. F., and Laraia P. J. (1971). Cyclic adenosine $3^{\prime} 5^{\prime}$-monophosphate in human lung. Biochimica et Biophysica Acta, 252, 160-164.

Karlberg, B. E., Henriksson, K. G., and Andersson, R. G. G. (1974). Cyclic adenosine 3'5'-monophosphate concentration in plasma, adipose tissue and skeletal muscle in normal subjects and in patients with hyper- and hypothyroidism. Journal of Clinical Endocrinology and Metabolism, 39, 96101 .

Leading article (1970). Cyclic AMP: The second messenger. Lancet, 2, 1119.

Lichtenstein, L. M., and Margolis, S. (1968). Histamine release in vitro: inhibition by catecholamines and methylxanthines. Science, 161, 902-903.

McFadden, J. R., Jr., and Linden, D. A. (1972). A reduction in maximum mid-expiratory flow rateA spirographic manifestation of small airway disease. American Journal of Medicine, 52, 725737.

Palmer, K. N. V., Gaddie, J., and Skinner, C. (1974). Alpha-adrenoceptor-blocking drugs in asthma (letter). British Medical Journal, 4, 409.

Patel, K. R., and Kerr, J. W. (1975). Alpha-receptorblocking drugs in bronchial asthma (letter). Lancet, 1, 348-349.

Pearson, R. M., Bending, M. R., Bulpitt, C. J., George, C. F., Hole, D. R., Williams, F. M., and Breckenridge, A. M. (1976). Trial of combination of guanethidine and exprenolol in hypertension. British Medical Journal, 1, 933-936.

Pihlajamäki, K., Kanto, J., and Iisalo, E. (1972). Human and animal studies on the interactions between glyphylline and isoprenaline. Journal of A sthma Research, 2, 255-261.

Rall, T. W., and West, T. C. (1953). The potentiation of cardiac inotropic responses to norepinephrine by theophylline. Journal of Pharmacology and Experimental Therapeutics, 139, 269-274.

Robinson, B. F., Epstein, S. E., Beiser, G. D., and Braunwald, E. (1966). Control of heart rate by the autonomic nervous system. Circulation Research, 19, 400-411.

Robinson, S., Pearcy, M., Brueckman, F. R., Nicholas, J. R., and Miller, D. I. (1953). Effects of atropine on heart rate and oxygen intake in working man. Journal of Applied Physiology, 5, 508-512.

Robison, G. A., Sutherland, E. W., and Butcher, R. W. (1971). Cyclic AMP, pp. 146-231. Academic Press, London and New York.

Veldstra, H. (1956). Synergism and potentiation. Pharmacological Reviews, 8, 339-387.

Wehmann, R. E., Blonde, L., and Steiner, A. L. (1974). Sources of cyclic nucleotides in plasma Journal of Clinical Investiation, 53, 173-179.

Requests for reprints to: Dr. I. A. Campbell, Respiratory Department, Bristol Royal Infirmary, Bristol. 